the responsibility for the general arrangements for children and to be the contact point between the accident and emergency department and the paediatric unit. More than this is needed, however: the causes of attendance vary from trauma, acute illness, social pathology, and child abuse to cot deaths, and this wide scatter justifies the further development of the subspecialty of paediatric accident and emergency medicine. Paediatricians with a special interest or total commitment to particular branches of the care of children have developed their subject and improved the standard of the care of children in those specialties. The exception is paediatric accident and emergency medicine. There are only three consultants-in Sheffield, Liverpool, and Dublin -and more of such posts should be established, possibly one in each region. Senior registrars in paediatrics might with profit spend some time during their training in such accident and emergency departments (or even in a general accident and emergency department) in the same way that senior registrars in accident and emergency medicine have to spend some time in a general paediatric unit. Other staffing improvements are needed: a senior nurse (grade 6) with a registered sick children's nurse qualification and a liaison health visitor should be appointed to each accident and emergency department. New accident and emergency departments should be sited only in hospitals having inpatient accommodation for children, and appropriate waiting, treatment, and other facilities for children should be provided.

The substance of these changes was almost all recommended 18 years ago in the memorandum on the management of accidents in childhood and later in the Court report. ${ }^{2}$ The joint paediatric committee of the Royal Colleges of Physicians and the British Paediatric Association made similar recommendations to the chief medical officers of England and Wales, Scotland, and Northern Ireland in 1983, and we believe that these will have the support of the Casualty Surgeons' Association (unpublished recommendation). It is time this Cinderella of services for children was transformed.

\section{R H JACKSON}

Former convener of the British Paediatric Association/British Association of Paediatric Surgeons' Joint Standing Committee on Chil thood Accidents and Medical Consultant,

Child Accident Prevention Trust,

London WC1N 3AZ

1 Standing Committee on Accidents in Childhood of the British Paediatric Association. Memorandum on the management of accidents in childhood. Br Med F 1967;iii: 103-5.

2 Committee on Child Health Services. Fit for the future. Vols 1 and 2. London: HMSO, 1976. (Court report.)

\section{Gridlock and incentives in NHS}

The National Health Service is trapped in gridlock and lacks the incentives to break out. That is the message from Professor Alain C Enthoven of Stanford University, who earlier this year spent several weeks as a fellow at $\mathrm{St}$ Catherine's College Oxford studying the management of the NHS. His conclusions (summarised at page 1067) are contained in a monograph, Reflections on the Management of the National Health Service, published by the Nuffield Provincial Hospitals Trust, which sponsored the visit. ${ }^{1}$ North America is a fertile source of flying critics of the NHS, but, fortunately, Professor Enthoven, a former Rhodes scholar, is knowledgable and constructive. Described as one of America's leading experts on the economics of health care by the Economist-which showed its appreciation of his ideas in a four page article ${ }^{2}$ - his analysis is sharp and his solutions radical.

Describing each country's health system as a product of its own history and culture, Enthoven offers no North American miracle cures and acknowledges that the NHS is Britain's democratic choice. The United States has equally serious problems, and he offers experience drawn from a battle against rising health care costs in his country of a ferocity that makes the arguments over the political, financial, and management troubles of the NHS genteel by comparison.

Gridlock, for those unfamiliar with New York, occurs when the streams of North/South traffic become so interlocked with the streams of East/West traffic that all vehicles are caught in an immovable mass. The NHS is held in the grip of similar interlocked forces that make real change difficult. These Enthoven lists as government imposed cash limits, consultants' long term contracts, general practitioners' contractual independence, nationally negotiated agreements with unionised staff, a lack of management incentives for improved performance, the institutional rule of "do no direct harm," politicisation that generates aversion to risk, the preference of politicians for cosmetic changes with short term electoral benefits, and a private sector "safety valve" that lessens the pressure for change from the articulate section of the public.

These forces are, indeed, powerful and immense political will would be needed to modify any of them. For example, what politician would care to invite consultants to accept short term contracts or suggest to general practitioners that their traditional independence should be restrained? As to the continuation of central negotiations, only last week the BMA council was vigorously supporting the Hospital Junior Staffs Committee in its complaint that a national agreement on standards of residential accommodation was being eroded by health authorities with tacit government approval ( $p$ 1062).

Viewed objectively, however, Enthoven has identified some vulnerable targets. Take consultants' contracts: to change the specialty mix of its medical staff, he points out, a regional health authority must wait for deaths and retirements. Ironically, the pressure for a change of mix arises largely from the profession's own success in advancing the frontiers of medicine, the growth of gastroenterology and geriatric medicine providing two recent examples. Certainly in today's high technology industries such a restraint on staff would be crippling. Indeed, it has been argued that the inability or reluctance to change has contributed greatly to Britain's industrial decline. Yet, to return to the NHS, there are dangers in introducing a limited term contract for consultants: appointments could be too readily subject to passing fashion or to local political or personality pressures. The idea of modifying contracts, however, will appeal to health service managers as well as politicians so the profession will need to marshal its arguments on the subject with care. It will find comfort as well as anguish in Enthoven's chapter on medical leadership. While sharply criticising the misuse of clinical freedom-particularly in the context of waiting lists and private practice-he supports the concept of doctors in management, drawing on American experience. "In the leading cost effective organised systems of care in the United States, systematic involvement of doctors in questions of resource use is considered absolutely essential to economy in medical care. Physicians make the key cost

\section{$\underline{\underline{T}}$} \section{\)} 인 $\overparen{\Omega}$

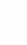

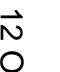

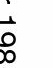

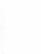


generating decisions. They set the tone for the rest of the organisation. They cannot be told to do something they don't believe in. They need to lead in the development of efficient care." With NHS consultants in danger of losing out in the Griffiths management reforms (pp 1062, 1065), this message has an added urgency.

On Griffiths Enthoven's understated style is particularly devastating. "While I am sympathetic to the thrust of the report . . . if the structure and incentives in the NHS are not changed more fundamentally, these recommendations are not likely to change much." For those grappling with the consequences of this "reform"-described as the biggest reorganisation the NHS has undergone-these words will bring no comfort. He identifies national uniformity and political haste as stultifying the aims of the management changes. With the departure of Kenneth Clarke from the Department of Health and Social Security the pressure for haste may lessen-though much damage has already been done. ${ }^{3}$ Even so, the Whitehall tradition of uniformity will be hard to overcome. Enthoven sees the solution in wider but more effective use of competitive tendering for catering, cleaning, and laundry services-the "entering wedge for a great deal of management improvement"; the purchase by districts of private sector medical care when this can be bought at a "good price"; a widespread use of pilot schemes before changes are introduced; and-the most provocative proposal of all-the substitution of positive incentives for existing perverse incentives, with the introduction of an "internal market model" for the NHS.

What does this last suggestion mean? The aim would be to enable managers to use resources most efficiently and this would be achieved as follows. Each district would receive RAWP based per capita revenue and capital allowances and would be responsible, as now, for providing and paying for comprehensive care for its resident population. It would be paid for emergency services to "outsiders" at a standard cost and for non-emergency services at negotiated prices. Hence in effect each authority would resemble an American health maintenance organisation (p 1068). Pay and working conditions would preferably be negotiated locally. Consultants and general practitioners would be contracted to district authorities, which could negotiate variable term contracts with appropriate incentives. Districts would be allowed, within limits, to borrow at government long term interest rates and to keep the proceeds of property sales. Services and assets could be bought and sold between districts, which would also be free to introduce management innovations.

Enthoven believes that such a market model would force the development of proper costing schemes and create much more cost efficiency and cost sensitivity among health authorities. He acknowledges that the model lacks incentives for decisions to be taken in the best interests of patients rather than of the authority. Though attracted by the idea of the patient choice available in America through competing hospital maintenance organisations-in themselves mini NHS's - he accepts that this would not be workable in Britain. But patients would be no worse off than they are already, and if the internal market model was found to be effective-presumably after suitable pilot studies-patients should benefit from a more effective and locally oriented service.

Medicopoliticians may well reject Enthoven's diagnosis and suggested treatment of the NHS's management ills. Ideological opponents of the private sector as well as sceptics who doubt its capabilities will also be critical. But, even shorn of its suggested links with the private sector, the internal market model could promote better management and loosen the gridlock in the NHS. It would be a tragedy if his ideas were not taken seriously, weighed in the balance, and tested in the small pilot schemes he advocates so powerfully.

\footnotetext{
1 Enthoven AC. Reflections on the management of the National Health Service. London: Nuffield Provincial Hospitals Trust, 1985.

Anonymous. Some reforms that might be politically feasible. Economist 1985 June 22:19-22.

3 Anonymous. Griffiths in action: not what the doctor ordered. Br Med $\mathcal{J} 1985 ; 291: 843-4$.
}

\title{
Treatment of chronic heart failure: a review of recent drug trials
}

\author{
DAVID P LIPKIN, PHILIP A POOLE-WILSON
}

The conventional treatment for congestive heart failure is diuretics (either a thiazide or a loop diuretic), some form of potassium replacement, and digoxin. Digoxin is specifically indicated for the control of atrial fibrillation but is also widely used in patients with heart failure who are in sinus rhythm. For mild, moderate, and even severe heart failure this treatment is effective in most patients. Fluid overload producing either peripheral oedema or pulmonary congestion is controlled, and symptoms are improved. A clinical problem exists only when despite conventional treatment patients continue to have symptoms, usually shortness of breath or fatigue.

What further treatment should then be introduced? New inotropic drugs have been and are being investigated in the belief that a more powerful positive inotropic agent without the toxic side effects of digoxin might be valuable in heart failure. Vasodilators have also been studied, since unloading the heart might directly relieve symptoms and retard the progressive functional deterioration of myocardial muscle. Numerous reports of the acute and chronic haemodynamic 